\title{
Neutron Capture Resonance Energy Identification of Indium by Time-of-Flight Method
}

\author{
Samyol Lee \\ Department of Radiological Science, Dongseo University, Jurae-dong, Sasang-gu, Busan, Korea

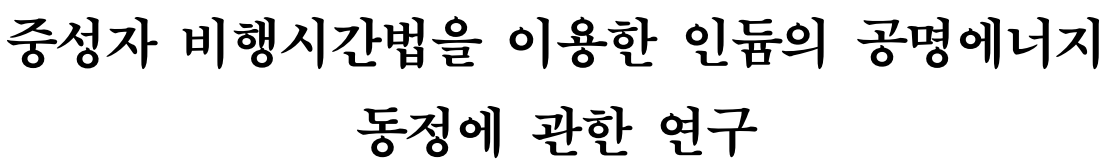

이삼열

동서대학교 방사선학과

\begin{abstract}
Prompt gamma ray from the natural Indium sample was measured by using an assembly of $\mathrm{BGO}\left(\mathrm{Bi}_{4} \mathrm{Ge}_{3} \mathrm{O}_{12}\right)$ scintillation detectors in the neutron energy region from 1 to $300 \mathrm{eV}$. The assembly was composed of 12 pieces of BGO. The spectrometer was composed geometrically as total energy absorption detector. 46-MeV electron linear accelerator which is located at Research Reactor Institute, Kyoto University used for neutron sources from photonuclear reaction. The measurement of the neutron capture resonances was performed to below neutron energy $1 \mathrm{keV}$, because of strong X-ray effect from photonuclear reaction in Ta target and short distance from the target to an assembly of detector. The distance of neutron flight path is $12.7 \pm 0.02 \mathrm{~m}$. The large neutron capture resonances were measured from 1 to $400 \mathrm{eV}$. The energy in the capture resonance was compared with the evaluated values. The large resonances were seen in the present measurement. General agreement can be seen between the present measurement and the previous evaluated data in relevant energy region. In the present study, we measured the continues resonance structure above $1 \mathrm{keV}$ neutron energy region. $91.49 \mathrm{eV}$ new neutron capture resonance was found in present measurement.
\end{abstract}

Key words: neutron capture, resonance energy, Time-of-flight method, Indium

\section{요야}

본 연구는 천연 인듐의 중성자폭획 후에 발생된 감마선을 12 개의 $\mathrm{BGO}\left(\mathrm{Bi}_{4} \mathrm{Ge}_{3} \mathrm{O}_{12}\right)$ 섬광검출기로 구성된 검출장치 를 이용하여 즉발감마선을 측정하여 중성자공명에의해서 발생된 감마선을 분석하여 중성자의 에너지 $1 \sim 300 \mathrm{eV}$ 영역에 대하여 공명에너지를 분석하였다. 사용되어진 검출장치는 시료에서 발생된 즉발감마선에 대하여 모든 감마 선을 측정할 수 있는 기하학적인 구조로 만들어졌다. 중성자원으로는 교토대학의 원자로연구소의 $46-\mathrm{MeV}$ 전자선 형가속기의 광핵반응에서 발생하는 중성자를 이용하였다. 중성자발생원으로부터 검출기까지의 거리가 $12.7 \pm 0.02$ $\mathrm{m}$ 이므로 광핵반응에서 발생하는 강한 X선의 영향을 고려하여 수 $\mathrm{keV}$ 영역이하의 중성자에너지에 대하여 중성자공 명을 측정하였다. 측정되어진 공명들은 $1 \mathrm{eV}$ 이상의 에너지 영역에서 거대 공명들을 측정하였고 이들 공명들은 이론 
에서 알려진 값들과 비교하였다. 본 연구를 통하여 기존에 알려진 거대 공명의 에너지를 확인하였고, $100 \mathrm{eV}$ 이상의 에너지 영역에서의 공명에너지들에 대한 평가에 의한 이론값들이 실제로 존재하는 공명임을 실험적으로 확인하였 다. $1 \mathrm{keV}$ 이상의 영역에 대하여는 공명이 연속적인 구조를 보이고 있음을 실험적으로 확인했으며 공명에 대하여 통 계적인 평가가 있어야함을 알았다. $91.49 \mathrm{eV}$ 공명은 본 연구를 통하여 처음 발견되어진 공명이라 볼 수 있다.

중심단어: 중성자포획, 공명에너지, 비행시간법, 인듐

\section{I. 서론}

중성자 포획핵반응에 대한 연구는 미국, 일본, 러시 아, 프랑스 등의 선진국에서는 수십 년 전부터 이미 막대한 연구비를 지원하여 국가적 차원에서 데이터를 구축해 오고 있다 ${ }^{[1]}$. 초기의 중성자 포획반응에 관한 연구는 원자로 개발 및 핵무기 개발을 주된 목적으로 연구가 시작되어 왔으나, 최근에는 미래형 원자로 개 발, 핵물리, 우주물리, 우주선의 방사선 피폭방지 설계 및 의료 방사선 치료·진단분야 등의 여러 분야에 방사 선에 대한 응용이 확대됨에 따라서 그 연구의 중요성 과 필요성이 커지고 있다.

특히, 중성자포획 핵반응에 대한 결과는 물질의 중 성자 포획 후 만들어지는 여기상태의 핵준위를 통한 핵구조 연구에 중요한 정보를 제공한다 ${ }^{[2]}$. 뿐만 아니 라, 그 결과는 최근 국제적으로 활발히 연구개발이 진 행되고 있는 고속 증식로(FBR: Fast Breeder Reactor)와 가속기 구동로(ADSR: Accelerator Driven System Reactor)의 노심설계, 차폐설계 및 원자로 열출력 계산 등을 위한 중요한 기초 자료로써 사용되어 진다 ${ }^{[3]}$. 원 자로의 노심속에서 생성되는 핵분열생성물(FPs: Fission Products) 및 희귀 악티나이드 원소(MA: Minor Actinide)들에 의한 중성자 거동의 변화들은 이런 중성 자반응에 대한 정보들을 통하여 이해하고 있다 ${ }^{[4]}$. 우 주물리학에 있어서도 우주의 진화 및 별들의 생성 이 론인 물질에 의한 중성자포획에 의해서 생성되는 s및 r-process의 모델 계산에 중성자 핵반응 정보는 별 의 진화과정을 이해하는데 매우 중요하다.

이와 같이 정확한 중성자 반응에 대한 정보를 측정 하는 것은 중요하며 그 중에서도 중성자에 대한 공명에 너지를 측정하는 것은 중요하다. 따라서 본 연구에서는 인듐(Indium)에 대한 중성자 공명에너지측정을 하였다.
천연 인듐 $(\mathrm{Z}=49)$ 은 질량수가 113 과 115 의 2 가지로 존재 하며 안정된 동위원소의 형태로 존재하고 있다. 각각의 존재비율은 4.29(A=113) \%와 95.71(A=115) \%이다 ${ }^{[5]}$. 특 히 인듐은 위에서 언급한 FPs에 속하는 물질로서 원자 로 노심속에서의 중성자속을 감속시키는 물질이기도 하다. 뿐만 아니라 $\mathrm{keV}$ 영역의 포획단면적은 행성의 원 소 합성에 있어서 s-process와 고속중성자 연구에 있어 서 중요한 정보이기도 하므로 정확한 단면적 측정이 요 구된다. 그러나 인듐에 대한 중성자포획공명 데이터는 $\mathrm{eV}$ 에너지영역에서 $\mathrm{keV}$ 영역에 이르는 측정 데이터의 양 및 질이 미흡하고, 미측정 에너지 영역도 있으며, 더 구나, 측정의 정밀도도 만족스럽지 못한 것이 현실이다. 인듐에 대한 연구는 미분중성자포획단면적을 측정한 결과들이 있으나 공명에너지에 대한 결과는 부족한 현 황이다 ${ }^{[6]}$.

본 연구는 일본 교토대학 원자로실험소(KURRI: Kyoto University, Research Reactor Institute)의 펄스 형태의 $46-\mathrm{MeV}$ 전자선형가속기를 이용한 핵반응에서 발생된 중성자를 이용하여, 중성자 비행시간(TOF: Time-OfFlight)법을 사용하여 얻어진 데이터를 이용하여 중성자 공명에너지에 대한 정확한 측정하였다.

\section{II. 측정}

본 연구에서는 천연인듐의 중성자포획에 따른 공명 에너지를 포획반응을 통하여 측정하였다. 사용되어진 중성자원은 일본 KURRI의 강력한 펄스 형태의 $46-\mathrm{MeV}$ 전자선형가속기로 가속된 고속의 전자선을 탄 탈(Ta: Tantalum) 표적에 조사시켜 광핵반응( $\mathrm{Y}, \mathrm{n})$ 에 의 해 발생된 중성자를 이용하였다. 중성자 에너지 결정 에 있어서는 중성자 TOF법을 사용하였고 얻어진 데 이터를 이용하여 중성자 공명에너지를 정확히 측정하 였다. 전자선형 가속기의 운전조건으로는 가속전자의 


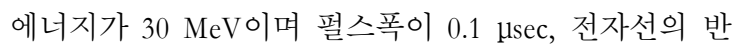
복 발생수가 $150 \mathrm{~Hz}$ 의 전자빔을 이용하였다. 사용되어 진 실험장치도를 그림 1 에 나타내었다. 그림에 나타낸 것과 같이 발생된 중성자빔은 시료에 효율적으로 집 속될 수 있도록 납, 파라핀, $\mathrm{B}_{4} \mathrm{C}+\mathrm{H}_{3} \mathrm{BO}_{3}$ 를 사용하여 차폐하였다. 실험에 사용되어진 시료로서는 금속판 형 태로서 가로 세로가 각각 $1.8 \mathrm{~cm} \mathrm{x} 1.8 \mathrm{~cm}$ 이며 두께는 $0.1 \mathrm{~mm}\left(0.09 \mathrm{~g} / \mathrm{cm}^{2}\right)$ 의 시료를 사용하였다. 이 두께는 공명들의 형태와 공명에너지를 고려하여 결정하였다. 포획감마선검출에 있어서는 중성자원으로 부터 약 $12.7 \pm 0.02 \mathrm{~m}$ 떨어진 곳에 위치한 전에너지 흡수형 감 마선 검출기인 12 의 $\mathrm{BGO}\left(\mathrm{Bi}_{4} \mathrm{Ge}_{3} \mathrm{O}_{12}\right) 5 \times 5 \times 7.5 \mathrm{~cm}^{3}$ 로 조합되어진 감마선 검출장치를 이용하여 측정을 하였다. 총 부피로는 2.25 liter로서 이것은 액체섬광검 출기의 약 $1 / 1000$ 배로 매우 밀도가 높아 효율적인 감 마선 측정이 가능한 검출기이다. 시료에 입사된 중성 자는 일부분 산란이 일어나게 되며 감마선검출에 있 어서 장해요인으로 작용한다. 따라서 $3 \mathrm{~mm}$ 두께의 ${ }^{6} \mathrm{LiF}$ 타일을 사용하여 검출기에 들어오는 산란중성자 를 효율적으로 차폐하였다. 검출기에서 발생된 신호들 은 FAST Com Tec's MPA/PC를 사용하여 2차원 측정 을 하였다.

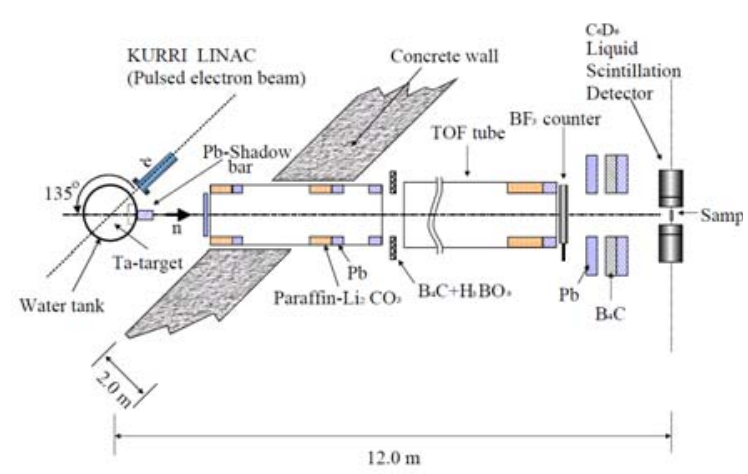

Fig 1. Experimental arrangement

본 연구에서는 중성자 포획에 따른 공명에너지를 중성자비행시간법을 이용하여 결정하였다. 이때 결정 되어지는 포획중성자의 에너지는 다음 식(1)에 나타내 었다. 여기에서 $\mathrm{L}$ 은 중성자발생원에서부터 검출기까 지의 거리이며 $\mathrm{t}$ 는 중성자의 비행시간을 의미한다.

$$
E(t)=\left(\frac{72.3 \times L}{t}\right)^{2}(M e V)
$$

즉 식에서 보는 바와 같이 운동에너지가 큰 중성자 의 경우 긴 거리를 짧은 시간에 도달 할 수 있음을 알 수 있다. 일반적으로 실험에 있어서는 중성자비행 거리는 고정되어 있으므로 중성자의 비행시간에 의해 서 중성자의 에너지가 결정되어 질수 있음을 식을 통 하여 알 수 있다. 실제 실험에서는 비행시간은 측정 장치의 채널수에 각 채널당 시간을 곱하여 중성자의 에너지가 결정되어 질 수 있다. 본 실험에서는 중성자 에너지 분해능을 고려하여 $0.25 \mu \mathrm{sec}$ 의 채널당 시간 $\left(\mathrm{Ch}_{\mathrm{t}}\right)$ 을 결정하였다. 총 채널 수(I)는 8192 를 선택하여 되도록 중성자에너지 분해능을 높이기 위해서 노력하 였다. 중성자 비행 거리의 경우 본 실험에서는 $12.7 \pm$ $0.02 \mathrm{~m}$ 이다.

따라서 중성자에너지를 결정하는 최종적인 식을 식 (2)에 나타내었다. 즉 중성자비행시간법에 의해서 측정 되어진 스펙트럼의 채널을 통하여 중성자에너지의 동 정이 가능해진다.

$$
E(t)=\left(\frac{72.3 \times L}{I \times C h_{t}}\right)^{2}=\left(\frac{72.3 \times 12.7}{I \times 0.25}\right)^{2}
$$

\section{III. 해석}

본 실험에서 얻어진 중성자 $\mathrm{TOF}$ 스펙트럼을 그림 $2 \sim 4$ 에 나타내었다. 얻어진 결과는 대표적인 이론결 과들인 Mugabghab ${ }^{[7]}$ 의 결과와 $\mathrm{ENDF} / \mathrm{B}-\mathrm{VI}[8]$ 의 결과 와 비교하였다. 대표적인 S-wave공명인 $1.45 \mathrm{eV}$ 공명을 비롯하여 $3.85,9.08,12.06,14.6,21.6,36.9,46.5,48.09$, 62.78, 69.38, 80.61, 83.34, 86.17, 94.4, 125.38, 132.1, 150.6, 165, 167.8, 177.92, 187.04, 204.99, 267.64, 276.7, $288.49,293.34 \mathrm{eV}$ 의 27 개의 공명의 경우는 본 연구의 결과와 일치하는 공명에너지를 보였다. 그러나 일부 공명들은 서로 불일치를 보였다. 이 결과들을 표 1 에 나타내어 정리하였다. 공명의 크기가 매우 작은 $4.7 \mathrm{eV}$ 공명의 경우 ENDF/B-VI 값과 일치함을 보였다. 이와 같이 $\mathrm{ENDF} / \mathrm{B}-\mathrm{VI}$ 의 값에는 제시되었으나 Mughabghab 
의 연구에서는 발견되지 못한 공명들은 4.7, 22.9, 24.9, $32.23,44.61,224.67,250.38 \mathrm{eV}$ 의 7 개의 공명들이었다. $6.86 \mathrm{eV}$ 공명의 경우에는 Mughabghab의 결과가 있으나 본 연구에서는 발견되지 않았고, $\mathrm{ENDF} / \mathrm{B}-\mathrm{VI}$ 값에서 도 제시되지 못하였다.

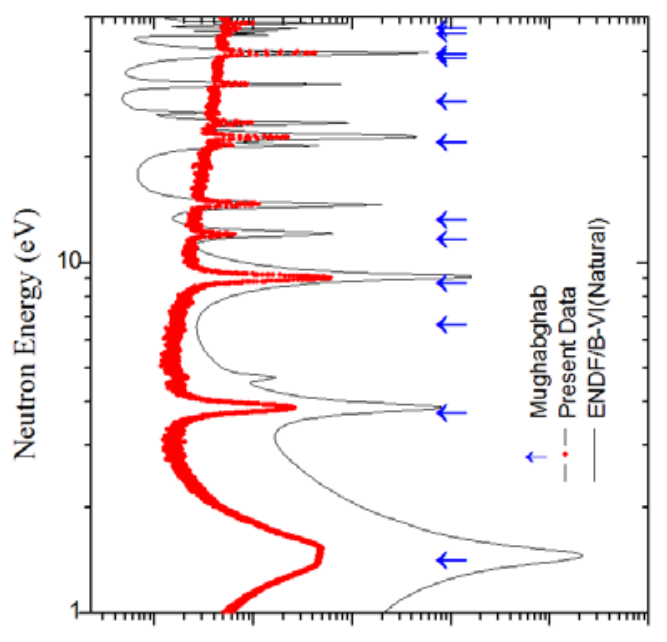

Realtive Capture Cross Yield (Counts)

Fig 2. Neutron TOF spectrum of Indium (Neutron Energy: $1 \sim 50 \mathrm{eV}$ )

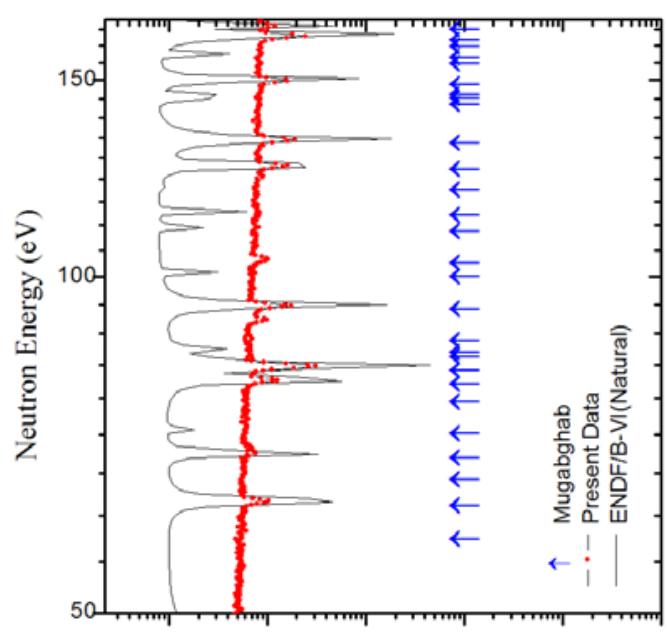

Realtive Capture Cross Yield (Counts)

Fig 3. Neutron TOF spectrum of Indium (Neutron Energy: 50 $170 \mathrm{eV}$ )

이런 공명들은 $6.86,29.67,40.66,66.4,77.89,85.5$, 88.4, 144.04, 146.9, 156.5, 162.2, 190.9, 192.4, 214.1, 219.7,
$226.6,246.7,249.5,264.5,275,282.3,285.1 \mathrm{eV}$ 로 22 개의 공명이었다.

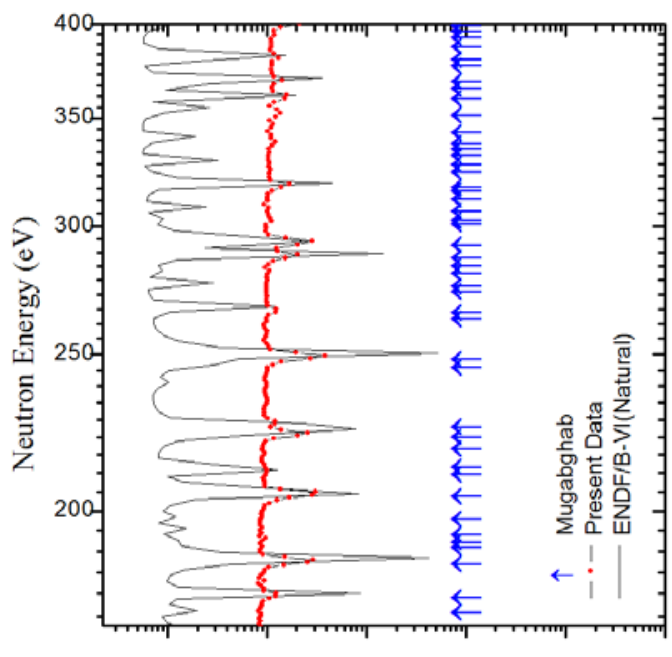

Realtive Capture Cross Yield (Counts)

Fig 4. Neutron TOF spectrum of Indium (Neutron Energy: : $170 \sim 400 \mathrm{eV}$ )

본 실험에서는 발견되지 않은 공명들은 $26.8,29.67$, 45.36, 72.94, 100.95, 114.39, 120.26, 145.66, 158.33, 173.5, $194.9,198.3,211.94 \mathrm{eV} 13$ 개 공명이었다. 이것들의 대 부분은 공명의 크기가 매우 작은 것으로 본 실험 장치 로서는 발견하기 매우 어려운 공명들이다. 따라서 이 들 공명에 대한 존재여부는 향후 성능이 매우 우수한 실험장비의 개발을 통하여 확인이 가능하다고 할 수 있다. 한편, $4.7 \mathrm{eV}$ 공명의 경우에는 매우 작아 확인이 어려웠으나 ENDF-VI의 결과를 통하여 검증할 수 있 는 계기가 되었다. 낮은 에너지에 대한 공명은 일반적 으로 이론에 의해서 계산되어진 ENDF-VI의 값과 전 체적으로 일치하는 경향을 보이고 있으나, $50 \mathrm{eV}$ 이상 의 영역에 대해서는 몇몇 일치하지 않은 공명들을 보 이고 있다. 예를 들어서 $91.49 \mathrm{eV}$ 공명의 경우는 본 연 구를 통하여 처음 발견되어진 공명이라 볼 수 있다. 그리고 $103.65 \mathrm{eV}$ 공명의 경우에는 $\mathrm{ENDF} / \mathrm{B}-\mathrm{VI}$ 에는 없는 공명으로 앞으로의 공명에 대한 이론계산에 중 요한 정보를 제공할 것으로 생각된다. 그리고 그림 4 에 보여진 것과 같이 약 $300 \mathrm{eV}$ 이상의 영역으로 갈 수 록 점점공명의 크기가 작아지고 조밀해 짐을 알 수 있었다. 따라서 고에너지 쪽으로 갈수록 보다 정밀한 장치를 이용한 공명 분석이 필요함을 알 수 있었다. 
"Journal of the Korean Society of Radiology, Volume 6, Number 5"

\section{IV. 결론}

본 연구에서는 천연인듐의 중성자포획에 따른 공명 에너지를 포획반응을 일본 KURRI의 강력한 펄스 형 태의 $46-\mathrm{MeV}$ 전자선형가속기를 통하여 측정하였고, 그 결과를 $\mathrm{ENDF} / \mathrm{B}-\mathrm{VI}$ 와 Mughabghab의 결과들과 비 교분석하였다. $300 \mathrm{eV}$ 이하의 영역에 대하여 본 실험의 결과와 일치하는 결과를 가진 공명은 27 개 였고,
Mughabghab의 결과에만 존재하는 공명은 22개 였다. 뿐만 아니라 본 연구에서는 발견되지 못한 공명들은 13 개 였으나 이것들의 공명존재의 여부는 보다 정밀도 가 높은 실험 장치를 이용한 고도의 공명분석을 통하 여 가능하리라 생각되어 진다. 더욱이 $91.49 \mathrm{eV}$ 공명의 경우는 본 연구를 통하여 처음 발견되어진 공명이라 볼 수 있으며 앞으로의 공명연구에 중요한 정보를 제 공했다고 보여진다.

Table 1. Compare the present neutron resonance energy with evaluated one

\begin{tabular}{|c|c|c|c|c|c|c|c|}
\hline & Present $(\mathrm{eV})$ & Mughaghab (eV) & ENDF/B-VI (eV) & & Present (eV) & Mughaghab (eV) & ENDF/B-VI (eV) \\
\hline 1 & 1.45 & 1.457 & 1.45 & 37 & - & 120.71 & 120.26 \\
\hline 2 & 3.85 & 3.85 & 3.85 & 38 & 125.38 & 125.88 & 125.38 \\
\hline 3 & 4.7 & - & 4.7 & 39 & 132.91 & 132.81 & 132.91 \\
\hline 4 & - & 6.86 & - & 40 & & 144.04 & - \\
\hline 5 & 9.08 & 9.04 & 9.08 & 41 & - & 145.76 & 145.66 \\
\hline 6 & 12.06 & 12.02 & 12.06 & 42 & - & 146.9 & - \\
\hline 7 & 14.6 & 13.6 & 14.6 & 43 & 150.6 & 150.1 & 150.6 \\
\hline 8 & 21.6 & 22.73 & 21.6 & 44 & - & 156.5 & - \\
\hline 9 & 22.9 & - & 22.9 & 45 & - & 158.6 & 158.33 \\
\hline 10 & 24.89 & - & 24.89 & 46 & - & 162.2 & - \\
\hline 11 & - & - & 26.8 & 47 & 165 & 164.4 & 165 \\
\hline 12 & - & 29.67 & - & 48 & 167.8 & 168 & 167.8 \\
\hline 13 & 32.23 & - & 32.23 & 49 & - & 174.2 & 173.5 \\
\hline 14 & 39.69 & 39.56 & 39.69 & 50 & 177.92 & 177.7 & 177.92 \\
\hline 15 & - & 40.66 & - & 51 & 187.04 & 186.4 & 187.04 \\
\hline 16 & 44.61 & - & 44.61 & 52 & - & 190.9 & - \\
\hline 17 & - & - & 45.36 & 53 & - & 192.4 & - \\
\hline 18 & 46.5 & 46.37 & 46.5 & 54 & - & 194.5 & 194.9 \\
\hline 19 & 48.09 & 48.14 & 48.09 & 55 & - & 198.7 & 198.3 \\
\hline 20 & - & 58.7 & - & 56 & 204.99 & 205.5 & 204.99 \\
\hline 21 & 62.78 & 62.93 & 62.78 & 57 & - & 211.9 & 211.94 \\
\hline 22 & - & 66.4 & - & 58 & - & 214.1 & - \\
\hline 23 & 69.38 & 69.47 & 69.38 & 59 & - & 219.7 & - \\
\hline 24 & - & 73.04 & 72.94 & 60 & - & 223.5 & - \\
\hline 25 & - & 77.89 & - & 61 & 224.67 & - & 224.67 \\
\hline 26 & 80.61 & 80.79 & 80.61 & 62 & - & २२६.6 & - \\
\hline 27 & 83.34 & 83.21 & 83.34 & 63 & - & 246.7 & - \\
\hline 28 & - & 85.5 & - & 64 & - & 249.5 & - \\
\hline 29 & 86.17 & 86.32 & 86.17 & 65 & 250.38 & - & 250.38 \\
\hline 30 & - & 88.4 & - & 66 & - & 264.5 & - \\
\hline 31 & 91.49 & - & - & 67 & 267.64 & 266.6 & 267.64 \\
\hline 32 & 94.4 & 94.3 & 94.4 & 68 & - & 275 & - \\
\hline 33 & - & 100.83 & 100.95 & 69 & 276.7 & 276.9 & 276.7 \\
\hline 34 & 103.65 & 103.7 & - & 70 & - & 282.3 & - \\
\hline 35 & - & 110.8 & 110.65 & 71 & - & 285.1 & - \\
\hline \multirow[t]{2}{*}{36} & - & 114.43 & 114.39 & 72 & 288.49 & 288.4 & 288.49 \\
\hline & & & & 73 & 293.34 & 293.7 & 293.34 \\
\hline
\end{tabular}




\section{감사의 글}

저자는 본 연구를 함에 있어서 도움을 주신 일본교 토대학교의 원자로연구소의 직원들의 도움에 감사함 을 드립니다. 그리고 본 연구는 2011년 동서대학교 프 런티어연구에 의해서 지원되었습니다.

\section{Reference}

[1] S. Harnood, M. Igashira, T. Matsumoto, S. Mizuno, and T. Ohsaki, J. Nucl. Sci. Tech. 37 (2000) 740.

[2] Mukaiyama, T., et al.: Conceptual study of actinide burner reactors, Proc. of 1988 Int Reactor Phys. Conf., Jackson Hale, Vol. IV, p.369, 1988.

[3] J. Tommasi et al., ibid., ANS, La Grange Park, Illinois, p.1252, 1993.

[4] K. Kobayashi, A. Yamanaka, I. Kimura, Journal of Nuclear Science and Technology, Vol. 31, p.1239, 1994.

[5] "Chart of the Nuclides 1996", Takayoshi Horiguchi et al, Department of Physics, Faculty of Science, Hiroshima University, 1-3-1 Kagamiyama, Higashi-Hiroshima, 739, Japan.

[6] J. Yoon, T. Ro, S. Lee, S. Yamamoto, and K. Kobayashi, Ann. Nucl. Energy 29 (2002) 1157.

[7] S. F. Mughabghab, M. Divadeenam and N. E. Holden, Neutron Cross Sections, Neutron Resonance Parameters and Thermal Cross Sections, Vol. 1, part A: Z=1-60(Academic Press, New York, 1981.

[8] "ENDF-201, Summary Documentation", BNL-NCS- 17541, MOD1 New Evaluation (ENDF/B-VI) 4th ed., P. F. ROSE, Ed., Brookhaven National Laboratory (1991). 